BULl. AUSTRAL. MATH. SOC.

$86 \mathrm{Al0}, 65 \mathrm{P} 05$

VOL. 34 (1986) $319-320$

\title{
MODELS OF FRONTOGENESIS
}

\author{
Michael JOHN REEDER
}

During summer in southeastern Australia the typical situation is for frontogenesis to occur in the trough region between two adjacent anticyclones. As well as providing a substantial data set on sumertime cold fronts, known locally as "cool-changes", recent field experiments of the Australian Cold Fronts Research Programme (ACFRP) have led to the development of a simple kinematic conceptual model. This thesis investigates the dynamics and evolution of the Australian summertime coolchange through a number of simple numerical models. Indeed, it is argued that the models provide a useful theoretical framework in which the dynamics of the cool-change may be understood.

A preamble to the thesis is given in Chapter 1. The dry anelastic equations of motion are introduced in Chapter 2 and a scale analysis of the viscous horizontal momentum equation is presented to determine the relevant force balances near a front. Finally a special case of two-dimensional frontogenesis is discussed.

In Chapter 3 a two-dimensional, anelastic, primitive equation, numerical model with a simple turbulence parameterization is integrated with Eady's linear normal mode solution for an unstable baroclinic wave as an initial condition. The structure of the surface front which develops after five days is compared with data obtained during the ACFRP. It is

Received 25 November 1985. Thesis submitted to Monash University, September 1985. Degree approved November 1985. Supervisor: Dr. R.K. Smith.

Copyright Clearance Centre, Inc. Serial-fee code: 0004-9727/86 $\$ A 2.00+0.00$. 
shown that the ridge-trough structure of an amplifying baroclinic wave and $i$ ts attendant surface front captures many of the important features of summertime cool-changes, together with the broadscale flow in which they develop.

Chapter 4 seeks to provide a dynamical basis for the conceptual model arising from the analysis of data collected during the ACFRP. To this end an idealized two-dimensional, anelastic, primitive equation, numerical model with a stretched vertical coordinate is developed. A model simulation is analysed in detail and compared both with the conceptual model and a three-dimensional nested grid model prediction of a classic summertime cold front over southeastern Australia.

In Chapter 5 the numerical model developed in the previous chapter is extended to include differential diurnal heating between land and sea. The interaction of a cold front, initially off-shore, with a neutrally stratified continental boundary layer is investigated. An intense prefrontal updraft develops late in the afternoon with cannot solely be attributed to a linear combination of the sea-breeze and frontal circulations. Concomitant with this development is increased surface convergence and vorticity, rapid frontogenesis and frontal acceleration. It is shown that the late afternoon intensification is a consequence of the neutral stratification ahead of the front. Comparison with data supports the model predictions.

Department of Mathematics, Monash University, Clayton, Victoria. 3168 